\title{
A Technology Enabled Learning Model in Healthcare during COVID-19
}

\author{
Habib Ur Rahman ${ }^{1, *}$, Nazir Ahmed Sangi ${ }^{2}$ and Moiz Uddin Ahmed ${ }^{1}$ \\ ${ }^{1}$ Department of Computer Science, Allama Iqbal Open University (AIOU), Islamabad, Pakistan \\ ${ }^{2}$ International Institute of Training (IIT), Islamabad, Pakistan \\ *Corresponding Author: Habib Ur Rahman. Email: habibswt@gmail.com \\ Received: 23 December 2020; Accepted: 10 February 2021
}

\begin{abstract}
The World Health Organization has warned about the spread of communicable and non-communicable diseases especially in the developing countries. The COVID-19 has also emerged as one of the most challengeable pandemics of the whole world. In current medical emergency, the virtual health education is much vital for handling alerts and outbreaks of diseases for a community of users. The Information and Communication Technology provide an opportunity to deal with the challenges related to handling alerts and outbreaks of diseases. The technology infrastructure in the developing countries is surging rise and can be used to develop Technology Enabled Learning Solutions for the basic health issues. This paper presents a technology model for virtual education of the masses during the recent era of pandemic diseases like COVID-19. The paper focuses on the health issues both in the developed and the developing countries. It also examines the technology options available for basic health education. Based on the literature review, opinion of health professionals and survey results on ICT accessibility, this paper presents a model of virtual online education on basic health issues for a rural community of users. A pragmatic approach (from literature) has been employed with constructivism theory in order to build the model. We have restricted our study to the geographical location of District Swat, Khyber Pakhtunkhwa and suggested sampling level of basic health education to address the research problems. A prototype with basic health education modules was also developed to demonstrate and test the model. The feedback has been found encouraging to develop a complete basic health education portal.
\end{abstract}

Keywords: ICT; technology in basic health; virtual learning

\section{Introduction}

Information and Communication Technology (ICT) is changing the landscape of societies as its use is increasing in every field of life [1]. The ICT infrastructure is pacing up at a very fast rate in both developed and developing countries [2]. This infrastructure includes mobile intensity, Internet access and availability of computer systems. The major chunk of ICT is based on Internet technologies which are disseminating huge amount of information to the masses especially in the developing countries [3]. The digital transformation is one of the top agendas of these growing societies. It is the assimilation of digitization into different areas of

This work is licensed under a Creative Commons Attribution 4.0 International License, which permits unrestricted use, distribution, and reproduction in any medium, provided the original work is properly cited. 
education, business and health [4]. It is also the transformation of basic health with the blend of technology where society delivers services to the customers at their doorstep. The services of education [5] and health [6] are the most important due to their influence on the society. Although technology is providing many opportunities yet there are challenges of providing seamless health and education services [7]. One of the challenges is the Development of Virtual Learning Systems for Health and Education during COVID-19 pandemics scenario.

The COVID-19 has resulted in closure of the educational institutions. More than 1.2 billion students are out of classrooms [8]. It has resulted in change of the educational mode from traditional class based learning to virtual education or e-learning. There are different approaches of virtual education like Computer Based Training (CBT), Online Learning and Technology Enhanced Learning (TEL) [9]. TEL refers to the technological support for learning activities. It overcomes the difficulties of distance between students and teachers and provides robust technology-based learning environment [10]. It also provides the source of communication and delivery mechanisms to support the process of learning. It utilizes ICT for the support of synchronous and asynchronous learnings. The synchronous systems are real time systems in which teachers and students are present at the same time. Asynchronous is offline communication between the stake holders in the form of digital content and presentation communication through email and forums, etc. [11]. This potential of technology can be used to develop health tutoring systems.

According to World Health Organization (WHO), basic health is also called primary health which covers common disease prevention, control, and treatment. Popular basic health problems are often the making of unhygienic activities including drinking contaminated and unclean water, food or weather shifts, widespread ignorance of disease awareness and (cause) knowledge [12]. The level of BH knowledge, however, varies in different countries as health initiatives and lifestyles (different in developed and developing countries), differ in health policies, commitments and financial support for each nation [13]. This is a very important practical strategy, especially given the low government expenditure on the health sector and the lack of facilities in local BH units throughout the country. A broad range of publicly accessible information may enable society and people to join hands with each other in preventing/combating outcomes rather than hoping that anything can be done by government. Here, researchers focus on ICT education infrastructure which schools (and the public) can use to access virtual education, health knowledge and common communicable diseases.

The COVID-19 has posed many challenges and has also opened up an opportunity to educate the out of school children and their families about the communicable diseases, i.e., diarrhea, cholera, typhoid fever, acute respiratory infection, hepatitis, skin diseases and COVID-19 at the same time [14-16]. In case of rural areas, the health facilities are less developed as compared to urban localities due to non-availability of health professionals, high cost of medical experts and geographical distances. Therefore, the potential of ICT may be utilized to develop technology driven health mentoring system, especially in rural area of a developing country like Pakistan. Keeping in view these challenges and opportunities, the emphasis of this research study is to propose a Technology Based Virtual Education Model for Basic Health that is referred to hereafter as the proposed VEBH Model. The rest of the paper is organized as: Basic health is detailed in Section 2. Usage of technologies in basic health education is described in Section 3. Preparation for building the VEBH model and algorithm for VEBH model workflow are briefed in Section 4. Implementation is also given in Section 5. Conclusions are provided in Section 6. References also are given in the last.

\section{Basic Health}

According to WHO [17], basic health deals with the fundamental conditions of the whole body for welfare of the society. It is the minimum information that each individual should acquire to stay vigorous and safe in a community they belong to. It includes control, prevention and care of the diseases, physical and psychological welfare. WHO also categorizes basic health problems into "communicable diseases" 
and "non-communicable diseases" [18]. Non-communicable diseases are not transferable from the infected persons whereas communicable diseases are transferable. The COVID-19 is an infectious disease and highly communicable [19]. Due to wide spread of diseases, WHO stresses on improving person or community health and declaring health education important and safe for rural and urban populations [20]. The requirement of health education is influenced by life styles, local health infrastructure, economic conditions and relevant policies and procedures. These parameters vary in different countries, therefore, the identification of health issues in developed and developing countries [21] are important before proposing any technology-based health education model and achieve a Sustainable Development Goal (SDG) [22].

\subsection{Basic Health Issues in Developed Countries}

Hypertension, mental wellbeing, cancer, diabetes, HIV/AIDS, respiratory infection, tuberculosis, overweight and obesity are the most prevalent diseases with a higher ratio in the United States [23]. Likewise, these diseases are widespread in European countries as well [24]. Similarly, in France, tuberculosis, suspected malaria, hypertension, diabetes, overweight/obesity, suspected HIV/AIDS, insomnia, sore throat and aches are most wide spread [25]. Similarly, hypertension, overweight/obesity, tobacco, suspected HIV/AIDS, malnutrition/physical inactivity and cancers have been identified in Chile [26]. Asthma, hypertension, diabetes, depression/mental health, overweight/obesity, osteoarthritis/carpal tunnel syndrome and high cholesterol are found excessive in Australia [27]. Peptic ulcer disease, hypertension, diabetes, overweight/obesity, suspected HIV/AIDS and osteoarthritis/carpal tunnel syndrome were Germany's most frequent diseases [28]. Likewise, the England Health Profile [29] identified lower respiratory infections, liver cancers, kidney diseases, hypertension, diabetes, drug/substance abuse, overweight/obesity, tobacco, alleged HIV/AIDS, malnutrition/physical inactivity and cancers. The COVID-19 has badly affected the societies of developed countries as its spread is exponential in USA and in majority of the European countries.

\subsection{Basic Health Issues in SAARC Countries}

The main reconstruction problems, Afghanistan's healthcare system consists of lack of stability and infrastructure, financial deprivation, weak coordination among authorities and fitness care providers, challenging access to healthcare facilities, unsuitable hospital conditions and few qualified people in healthcare [30]. According to Ali [31] and El-Saharty et al. [32], Bangladesh is facing double disease burden due to large population diversity. Similarly, they further described that the most prevalent communicable diseases are hepatitis, HIV/AIDS, suspected malaria, measles and rubella etc. Diabetes, cardiovascular diseases, hypertension, stroke and cancer are also non-communicable diseases in Bhutan [33]. The most common health issues include diarrhea, intestinal worms, respiratory infection, suspected malaria, skin infections, eye infection, hypertension and malnutrition. In this country too, chronic kidney disease, heart disease, diabetes and tuberculosis are high [34]. According to Dhara et al. [35] in India, the most prevalent diseases are diarrheal diseases, respiratory infections, tuberculosis, heart disease, suspected malaria, dengue fever, malnutrition, oral diseases, kidney disease, HIV/AIDS diabetes, cancers and tumors [36]. According to WHO, the most common diseases of Maldives are acute respiratory infection, diarrhea, conjunctivitis, suspected malaria, HIV/AIDS, tuberculosis, measles and dengue fever. There have also been health illnesses, hypertension, diabetes and liver diseases [37]. The most common health problems in Nepal are respiratory infections, tuberculosis, diarrhea, measles, heart diseases, diabetes, tetanus and autoimmune disorders [38]. In Sri Lanka, the most common diseases are diarrhea, respiratory infection, dengue fever, HIV/AIDS, tuberculosis, flu, heart disease, diabetes, kidney disease and cancer $[39,40]$. The COVID-19 has also spread in the SAARC countries. The first confirmed case was found in Nepal in a man who came back from Wuhan China. The other countries are also badly affected by the pandemic and there is a continuous rise of infections during the second wave of COVID-19. Millions of 
people have suffered from the pandemic and more to come. There is a dire need to educate the people especially in the rural areas of these countries.

\subsection{Basic Health Issues in Pakistan}

In Pakistan; diarrhea, acute respiratory infections (ARI), influenza, tuberculosis, etc. are communicable diseases and diabetes, obesity, cardiovascular disorders, malignancies, etc. are referred to as noncommunicable diseases [41,42]. According to Khadim [43], more than 60 million residents have no penny to address basic health issues in Pakistan. Pakistan has the worst state for basic health problems which are rising day by day due to unhygienic food and drinking water. The most common basic health problems in Pakistan are communicable diseases and some minor non-communicable diseases [44,45].

According to Khan et al. [45], the most frequent cases in a rural area of Swat are acute respiratory infections, gastrointestinal diseases, hepatitis and typhoid fever. The study reported that hepatitis, diarrhea, typhoid fever and skin infection diseases are high in occurrence due to unhygienic and polluted drinking water. According to District Health Officer Swat (2020), ARI (lower and upper), acute diarrhea, bloody diarrhea, typhoid fever, worm infestations, acute viral hepatitis, suspected malaria, suspected measles, unexplained fever, scabies/skin infection, tuberculosis and COVID-19 are the most common disease found on males and females. The second wave arrival of COVID-19 has been announced by the government. The daily cases of infections and deaths are rising and Government has imposed restrictions on the public gatherings. Basic health information and awareness were also established at high school level [45] for basic health-related problems and their solution. If the local adults and teenage students (and families) are well informed regarding knowledge and warnings about infectious illness, precautionary steps could be taken by communities and societies and major accidents could be avoided.

\section{Usage of Technology in Basic Health Education}

The trend of using technology is increasing to meet the challenges of various fields including the basic health education. The COVID-19 has opened up the ways of educating the masses at their homes. The technology is providing many possibilities for the delivery of health knowledge, i.e., preparation of health tutorials, health information portals, telemedicine systems and health websites.

\subsection{Mobile Phones}

Mobile phone is one of the most commonly available devices for communication because of its high intensity and growth rate throughout the world [46]. The device can effectively be used to deliver health information and knowledge in urban and rural areas across the globe [47]. The smart phones are the newer version of mobile devices which are capable to interact with multimedia applications, web browsing and act as minicomputer systems. Smart phones are common in every part of the world including the developed and the developing countries. Valle [48] studied the effectiveness of smart phone for medical education in a clinical environment. The positive impact was found dominant as compared to negative impression and its more vibrant use was recommended in health education. Latif [49] studied the effectiveness of smart phone in medical teaching and ranked the device as a powerful tool for medical education. Mobile applications for health education are available for iPhone and Android devices. Some of the applications focus on explaining the internal structure of human and animals and simulating the parts and functions of living organisms [50]. There are other applications which educate the patients about some pandemic diseases.

\subsection{Multimedia}

Multimedia is the collection of media objects like text, animations, audio and video. Multimedia instruction objects can be used in healthcare for training and education purposes. Multimedia course 
wares were developed for medical teaching [51]. The feedback of students was positive and encouraging. In another study, the effectiveness of multimedia tweets was investigated. The re-tweets were found more informative and influential among the targeted users [52]. They also recognized the learning capability of multimedia objects. The significance of e-learning objects was studied [53] on the basis of ten years feedback in Korean medical colleges. It was revealed that multimedia resources may be strengthened for education and training. During COVID-19, the perspective of distance learning was investigated for medical education. The overall satisfaction rate was found high with the use of multimedia objects and e-learning tools [54]. One more study recommended that shortage of healthcare professionals and time barriers could be overcome by providing multimedia education to diabetic patients [55].

\subsection{Personal Digital Assistants}

Personal Digital Assistants are small computers that act as hand held PCs. Mostly, they were used in classrooms for listening audios/videos in addition to face to face lectures. They were also used by medical students for submitting questions and assignments. The literature has also reported the use of PDA for patient record management and decision making for the treatment [56]. However, with the advent of technology, the PDAs have been replaced by the smart phones.

\subsection{Social Media}

Social Media is the knowledge sharing platform for the dissemination of information. It is used to share the thoughts, interests and other ideas of expressions via social media applications. There are different social media platforms available like social networking sites, blogs, wikis etc. One of the most famous and commonly is Facebook which is used by every age group and different schools of thought. Its popularity makes it useful for the delivery of health education. The literature has reported extensive use of social media in medical and health fields [57]. It can effectively be used to promote public health education and professional development of doctors and para-medical staff [58]. It has been found useful for hospitals and health education [59]. A study during pandemic revealed that Twitter can be used to communicate important health tips and events for health education [60].

\subsection{Simulations}

Simulation is an artificial environment of a system or process that portrays to operate on real parameters. The potential of simulation can be used in health care and medical education. It has proven helpful to take experience of a real environment by going thorough medical treatment, working in Intensive Care Unit (ICU) and handling emergency situations at hospitals and homes. It has been found valuable for training of doctors and para-medical staff [61]. The development of simulations is expensive, therefore, it is not suitable for basic health education as compared to other available technologies.

\subsection{Web based Tutorials}

Web commonly known as World Wide Web (WWW) is the collection of pages connected via hyperlink. Web based tutorials are accessible through the Internet and are widely used in health education. A web-based course on patients was developed for medical students. It was found useful in distance learning paradigm [62]. In another effort, the interactive web-based lectures for health education have been developed. It is a collaborative effort of health professionals and experts of library sciences [63] and are found useful for health education. One study investigated that the perception of school mentors for developing a webbased tutorial regarding mental health education. The feedback recommended adaptive rich contents for such a sensitive system [64]. One more study demonstrated the development of self-paced materials and case studies to teach the epilepsy issues during the pandemic [65]. WWW has been found as one of the most effective and cheap mediums to teach on the health issues and proposed remedies. 


\subsection{Complex Adaptive and Expert Systems}

Complex Adaptive Systems (CAS) are agent handlers with interactive and adaptive features. They perceive the environment and learn from the experience. CAS has been used in health care sector for scaling up the health facilities. The isolated healthcare incidents have been evaluated by using CAS. These incidents are related to organizational development and the management of health workers [66].

Expert systems are another dimension of specialized applications that use Artificial Intelligence for the decision making. Public health expert systems analyze health data and generate expert advice for health decision making [67]. Public health expert systems are much relevant to interpret the data on surveillance diseases and to disseminate awareness and information to avoid any outbreak. But, the expert information and knowledge system for public health is still a question mark especially in current scenario of medical emergency during COVID-19 pandemic.

Many avenues of technology are available for health education. They include health portals and electronic health records, telemedicine services, tele-ICU services and health information networks which help improve and promote health by assisting us to detect, diagnose, prevent, monitor and treat diseases and manage our lifestyle through improving our wellness and quality of life.

\section{Preparation for Building the VEBH Model}

Following the literature review related to health and technology, survey results and our previous work done [68-70] and extension of OLIVE e-learning framework [71], the following approach was laid down to propose the model:

- The model of virtual education will be available for access over a public Internet or mobile data network.

- The users will be any personally supported student, teacher, doctor or public educationist.

- The model is to be implemented using open source tools.

This is an exercise on designing a level of knowledge. However, it wasn't full-blown medical and technical information to students, but handy and simple knowledge. It should be in a plain language and easy to understand, but cover other common aspects of the disease(s) included in the knowledgebase.

We used pragmatic approach with constructive theory for development of VEBH Model [72]. The realistic approach focuses on real-life situations, rather than logically inclined. In a pragmatic approach [73] in its presentation sense, the problems or issues are identified and a series of research inquiries are undertaken and decisions are made on the real situations as they can be encountered in different phases of the problem. A case study of real-life scenarios is discussed in this research, and a model has been proposed in the first scenario, we restricted our study to the geographical location (Swat District: A rural area in Pakistan) and suggested sampling level of education (High School) to study the research difficulties and the background problems of different aspects [68-70].

\subsection{Virtual Education for Basic Health (VEBH)}

We defined the final model here and the components thereof. The proposed VEBH Model was discussed in numerous conferences with healthcare and educational professionals [67-69]. The model was updated as shown in Fig. 1 as extracted from the literature review of virtual education and basic health issues [64], addressing their recommendation and comments for the proposed model.

\subsubsection{VEBH Application}

VEBH is a knowledgebase system which uses basic health data and information in the VEBH Model for inputs and extraction. It shows the details and knowledge of basic health conditions, advanced health 
diseases, national diseases, seasonal diseases and pandemic like COVID-19. Analysis is dependent on users and disease data that are linked to an expert system module. It is interconnected via portal for processing, editing, updating, and collecting data and information for learning and analyzing to generate areas of warning and outbreak, if any.

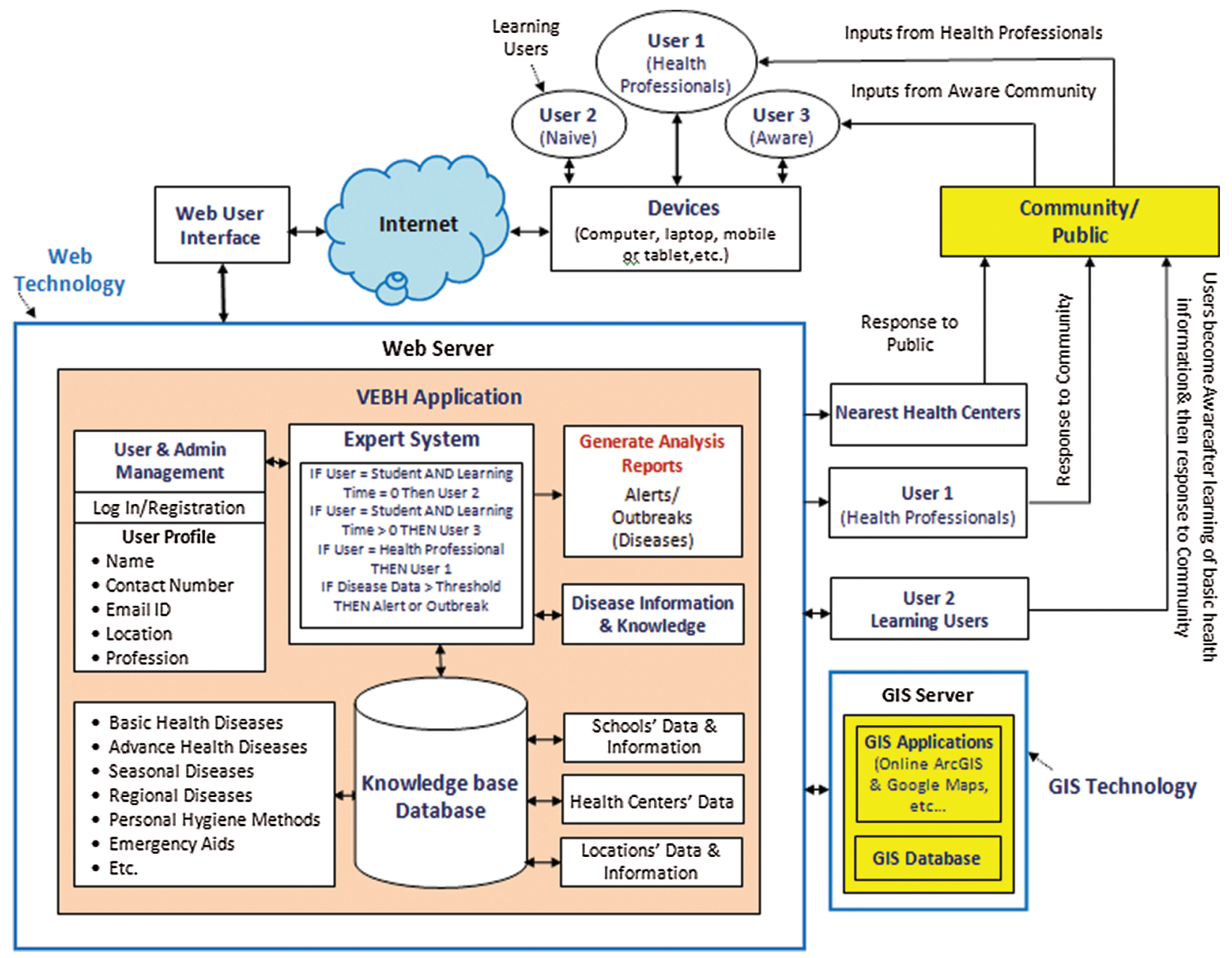

Figure 1: VEBH model and its components

\subsubsection{User and Admin Management}

Our proposed knowledgebase model has a new user registration module and an existing user login. It manages data profiles of users for their identity which consists of user name, contact number, email ID, occupation, location and image.

\subsubsection{Users}

Users mean end-users of the knowledgebase VEBH application that are being used in the VEBH Model. There are three types of users in the model (user 1, user 2, and user 3). User 1 consists of health professionals who provide inputs to the VEBH according to the information and experience of their areas, seasons and frequently occurring diseases. User 2 consists of naive users (students) who are unfamiliar with the information and knowledge about basic health conditions. They use the knowledgebase application of VEBH to learn the information and knowledge about basic health illnesses. User 3 consists of 
knowledgeable users (students) and comes from user 2 who has become aware of the information and knowledge about basic health diseases.

\subsubsection{Devices}

Users can access our proposed VEBH knowledgebase application for basic health learning and inputs using any kind of electronic device. Use of a computer, laptop or smart phone, etc., are not limited. VEBH application is a compatible application of any electronic device.

\subsubsection{Internet}

It is an integral part of the functioning of the knowledgebase of VEBH and its interlinked components within the VEBH model. Our proposed model is based on the Internet to provide teaching to remote learners in a hard-rural area.

\subsubsection{Web Technology}

Our proposed VEBH knowledgebase application uses web technologies such as HTML, XML, CSS, PHP, JavaScript, MYSQL, HTTP and numerous multimedia sources such as text, audio, video, and hybrid.

\subsubsection{Web Server}

The VEBH information-based framework was hosted on a web server in our proposed VEBH model. A web server is a computer program that stores, processes and transmits web applications as requested by users. To request VEBH knowledgebase application from a web server, use a domain name in a web browser.

\subsubsection{Web User Interface}

It is a graphical user interconnection bridge between users and web servers through which users demand knowledgebase application from VEBH. Users can navigate the VEBH knowledgebase program by using Google Chrome, Mozilla, or Internet Explorer.

\subsubsection{Web-based Expert System}

The VEBH model has some features of an expert system for addressing multiple complex community health issues. A web-based expert system uses decision-making and problem-solving strategies. It is also linked with GIS technology to extract and analyze data and information about the location of users and the regional diseases. It is also connected with a knowledgebase for data, information collection and extraction. It gathers relevant information from the database and then analyzes it with group entries. If an alert or outbreak occurs, then the program sends notifications to health practitioners and the nearest health centers for their response to the alarm/outbreak to populations.

\subsubsection{Knowledgebase}

This is the main database which consists of information and knowledge about health diseases. It also contains data and information from schools and health centers. Similarly, GIS types such as location data (coordinates) from schools, health centers, users and diseases are also stored in this database. It also has information on basic health illnesses, advanced health illnesses, regional illnesses, seasonal diseases, personal hygiene practices, first aids etc. It can be edited, removed, and updated as needed.

\subsubsection{General Reports}

The expert system is capable to analyze the data and produce the reports. It is composed of alerts and outbreaks of any disease that has occurred within the population. These reports are forwarded to the affected community, the nearest health centers and health professionals for disease-based response.

\subsubsection{GIS Technology}

The GIS technology works to classify and evaluate the locations. The GIS technology uses Google maps to store, record, search, and view related school and health facility location data. The warning created to any disease 
will be displayed on the map to make it easily accessible for health professionals and health centers. GIS applications such as Online ESRI ArcGIS and Google maps are used inside the repository under GIS technology.

\subsection{Algorithm for VEBH Model Workflow}

The proposed VEBH model workflow algorithm is shown in Fig. 2. Step 1 initializes all variables that were included for VEBH model startup. It initializes the naïve students, knowledgeable students, health professionals, nearest health centers, high schools, basic health problems, and communities. In step 2, the students at schools begin learning and gain knowledge of basic health information. Users start VEBH model in step 3, this may be for learning or input purposes. Similarly, step 4 judges the users for health professionals who provide their inputs on information about diseases that are stored in knowledgebase. Step 5 decides the users for naïve students who begin learning the information and knowledge about basic health diseases. If the naïve students (user 2) learn, they become conscious students (user 3). The trained students will increase in step 6 and they will replicate at home or in their community. The educated students would, in future, become a stable society. These users can offer their inputs in their group regarding diseases that have occurred, as shown in step 7. When the naive students know (user 2), they become attentive students (user 3). In step 6, the educated students should increase and repeat at home or in their group. In the future, the educated students will become a prosperous society. As shown in step 7, these users may give their feedback in their community about the illnesses that have occurred. In step 8, the VEBH system generates alerts with respect to trained students' inputs and send to health professionals and nearest health centers for quick response to relevant community. Step 9 determines the new users (i.e., naive students) and start step 5 again for continues process.

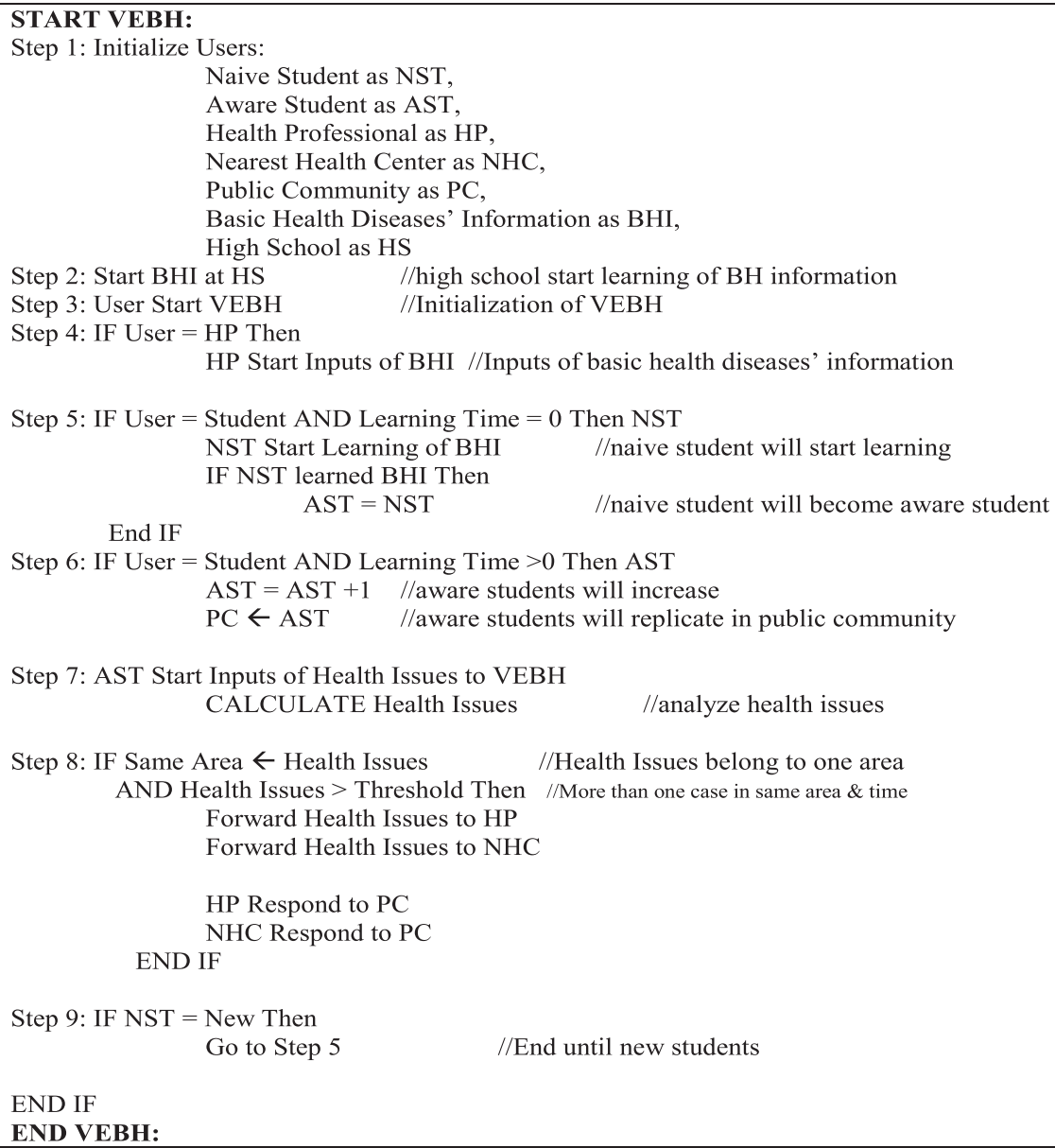

Figure 2: Algorithm for VEBH model 


\section{Implementation}

The VEBH model's front interface consists of several sub-modules such as learning of community diseases, Google maps, school information, information on health modules, methods of personal hygiene information, seasonal diseases substantial links and videos, survey (MCQs), VEBH and My account.

An initial prototype has been developed using PHP with MySQL at the backend. It includes basic health education learning modules, a calendar and a search box as shown in Fig. 3. Initial knowledgebase was developed for COVID-19, upper Respiratory tract infection, lower respiratory tract infection, hepatitis, typhoid fever, diarrhea, skin infection and suspected malaria.

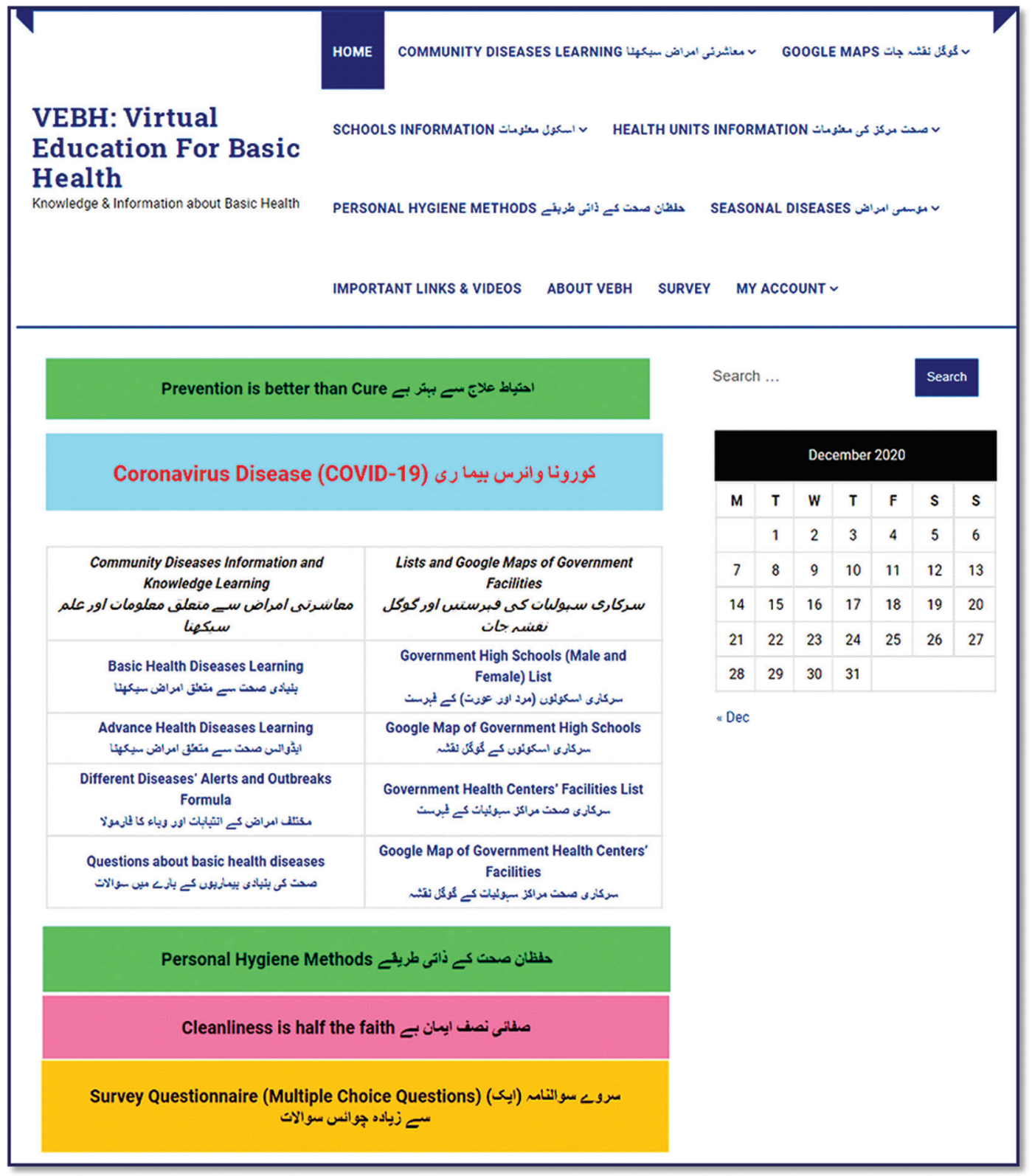

Figure 3: VEBH Prototype (Homepage) 
The prototype was presented to the students and health professionals of a rural community. Their feedback was encouraging for the development of a complete health informatics and educational portal [69].

\section{Conclusions}

A TEL based health education system has been proposed in this study. A literature survey was conducted to evaluate the basic health issues and the technological opportunities available. The available technology options were evaluated in the context of rural area of a developing country like Pakistan. The technology infrastructure and accessibility of Internet and mobile phones were evaluated to determine the strength and intensity of ICT. The health professionals were interviewed to highlight the basic health issues, their symptoms and remedy to deal with the challenges. The remedies were compiled to develop health tutorials for basic health education. A knowledge-base of health was prepared keeping in view the literature and opinion of health professionals.

As found in the feedback survey, the basic ICT infrastructure, i.e. computers, Internet and smart devices were available with the targeted sample. Therefore, as in the current scenario, the virtual model is much needed, especially experienced due to the recent Corona virus (COVID-19) pandemic. The virtual education model has been described as an integral model of support. As part of this research study, the model was later designed and built. It was confirmed by the health practitioners and educational experts. We used the pragmatic approach/systematic creation of knowledgebase software implementation under waterfall method. We developed a standardized model for Virtual Education, Basic Health and then the two were merged into the Virtual Education for Basic Health (VEBH). Considering the public ICT infrastructure and Internet/mobile devices, it is an effective standardized knowledgebase model for health education and information access. It was piloted for a rural area and can be extended in other localities. The model covers various aspects of basic health issues such as common inputs of information, alarms, causes, symptoms, preventive cares, primary cares, potential cures, referral to medical professionals, location of nearest health units and reports (alerts and outbreaks). It contains meta-database of information about basic health disorders, schools, and basic health units. It can be accessed from anywhere, from any Internet access device like; computer, laptop, and/or smart phone etc., at any time. Similarly, the knowledgebase includes information about common diseases in the basic health section. The VEBH model also includes an expert framework for three levels, of users. The user 1, i.e., health professional gives information about diseases. The user 2, i.e., naïve learner can access the tutorials for their learning. Finally, the user 3, the knowledgeable students can also use the system (within the community). If they find symptoms of any pandemic disease, they feed into the system. The health professionals evaluate all the inputs stored in the knowledgebase and decide on further action, i.e., generate alert/outbreak notification information within the group and forward it to nearest health centers and health professionals. In future, it may be expanded to other disease affected areas and clusters.

Funding Statement: The authors received no specific funding for this study.

Conflicts of Interest: The authors declare that they have no conflicts of interest to report regarding the present study.

\section{References}

[1] J. C. Bieser and L. M. Hilty, "Assessing indirect environmental effects of information and communication technology (ICT): A systematic literature review," Sustainability, vol. 10, no. 8, pp. 2662-2619, 2018.

[2] B. S. Sergi, E. G. Popkova, A. V. Bogoviz and J. V. Ragulina, "Entrepreneurship and economic growth: The experience of developed and developing countries," in Entrepreneurship and Development in the 21st Century. Emerald publishing limited, pp. 3-32, 2019. 
[3] M. I. Manda and S. Ben Dhaou, "Responding to the challenges and opportunities in the 4th Industrial revolution in developing countries," in Proc. of the 12th Int. Conf. on Theory and Practice of Electronic Governance, pp. 244-253, 2019.

[4] D. Ciuriak and M. Ptashkina, "Leveraging the digital transformation for development: A global south strategy for the data-driven economy," Center for International Governance Innovation, Policy Brief No. 148, 2019.

[5] X. Huang, "New reflections on higher education and social services in the new era," in Proc. in Int. Conf. on Modern Educational Technology and Innovation and Entrepreneurship (ICMETIE), Atlantis Press, pp. 522-525, 2020.

[6] F. Altan, A. Ekiyor and D. Unalan, "Health services delivery and satisfaction," in Quality Management for Competitive Advantage in Global Markets, J. Saiz-Álvarez, B. Olalla-Caballero, (Ed.), Pennsylvania: IGI Global, pp. 95-108, 2020.

[7] C. Avgerou, N. Hayes and R. L. La Rovere, "Growth in ICT uptake in developing countries: new users, new uses, new challenges," Journal of Information Technology, vol. 31, no. 4, pp. 329-333, 2016.

[8] K. Naidu and K. Naidu, "A study on emergency E learning in the wake of COVID-19," Dogo Rangsang Research Journal, vol. 10, no. 7, pp. 46-52, 2020.

[9] M. Kian, "Challenges of virtual education: A report of what are not learned," Interdisciplinary Journal of Virtual Learning in Medical Sciences, vol. 5, no. 3, pp. 11-21, 2020.

[10] M. U. Ahmed, N. A. Sangi and A. Mahmood, "A learner model for adaptable e-learning interaction," Int. Journal of Advanced Computer Science and Applications (IJACSA), vol. 8, no. 6, pp. 139-147, 2017.

[11] M. U. A. Siddiqui and S. Hussain, "A hybrid e-learning model in a localized environment," Pan Common Wealth Forum, vol. 21, no. 172, pp. 1-8, 2016.

[12] World Health Organization, "Primary Health Care,” 2019. [Online]. Available: https://www.who.int/news-room/ fact-sheets/detail/primary-health-care.

[13] M. H. Imani-Nasab, H. Seyedin, B. Yazdizadeh and R. Majdzadeh, "A qualitative assessment of the evidence utilization for health policy-making on the basis of SUPPORT tools in a developing country," Int. Journal of Health Policy and Management, vol. 6, no. 8, pp. 457-465, 2017.

[14] Y. Qi, L. H. Chen and L. Zhang, "Public practice, attitude and knowledge of corona virus disease," Journal of Tropical Medicine, vol. 14, no. 9, pp. 145-149, 2020.

[15] S. D. Pitlik, "COVID-19 compared to other pandemic diseases," Rambam Maimonides Medical Journal, vol. 11, no. 3, pp. e0027, 2020.

[16] D. M. Morens and A. S. Fauci, "Emerging pandemic diseases: How we got to COVID-19," Cell, vol. 182, no. 5, pp. 1077-1092, 2020.

[17] World Health Organization, "Ottawa Charter for Health Promotion," in An Int. Conf. on Health Promotion: The Move Towards a New Public Health, Ottawa, Ontario, Canada, WHO, November 17-21, 1986.

[18] A. Boutayeb, "The double burden of communicable and non-communicable diseases in developing countries," Transactions of the Royal Society of Tropical Medicine and Hygiene, vol. 100, no. 3, pp. 191-199, 2006.

[19] D. Bacherini, I. Biagini, C. Lenzetti, G. Virgili, S. Rizzo et al., "The COVID-19 pandemic from an ophthalmologist's perspective," Trends in Molecular Medicine, vol. 26, no. 6, pp. 529-531, 2020.

[20] M. Minkler and N. Wallerstein, "Improving health through community organization and community building," In: Community Organizing and Community Building for Health, 2nd ed., 30. New Jersey, USA: The State University of New Jersey, 277-300, 2004.

[21] A. Nawaz, X. Su, Q. M. U. Din, M. I. Khalid, M. Bilal et al., "Identification of the H\&S (health and safety factors) involved in infrastructure projects in developing countries-A sequential mixed method approach of OLMTproject," Int. Journal of Environmental Research and Public Health, vol. 17, no. 2, pp. 635, 2020.

[22] A. R. Nunes, K. Lee and T. O'Riordan, "The importance of an integrating framework for achieving the Sustainable Development Goals: the example of health and well-being," BMJ Global Health, vol. 1, no. 3, pp. e000068, 2016.

[23] F. Sultan and A. Khan, "Infectious diseases in Pakistan: a clear and present danger," Lancet, vol. 381, no. 9884, pp. 2138-2140, 2013. 
[24] European Commission, "Public Health Major diseases," 2020. [Online]. Available: https://ec.europa.eu/health/ major_chronic_diseases/diseases_en.

[25] Statista Research Department, "Main health problems in France in 2015," Statista, 2020. [Online]. Available: https://www.statista.com/statistics/764693/main-problems-health-la-france/.

[26] OECD Reviews of Public Health: Chile, “A Healthier Tomorrow,” 2020. [Online]. Available: https:/www.oecd. org/health/health-systems/OECD-Reviews-of-Public-Health-Chile-Assessment-and-recommendations.pdf.

[27] University of Sydney, "The 6 top chronic health issues affecting Australians," 2020. [Online]. Available: https://www. sydney.edu.au/news-opinion/news/2017/03/10/the-six-top-chronic-health-issues-affecting-australians-new-res.html.

[28] R. Lee, “Top diseases in Germany,” The Borgen Project, 2020. [Online]. Available: https://borgenproject.org/topdiseases-in-germany/.

[29] Health Profile for England, "Major causes of death and how they have changed," Gov. UK, 2020. [Online]. Available: https://www.gov.uk/government/publications/health-profile-for-england/chapter-2-major-causes-ofdeath-and-how-they-have-changed.

[30] A. L. Wagner, M. Y. Mubarak, L. E. Johnson, J. M. Porth, J. E. Yousif et al., "Trends of vaccine-preventable diseases in Afghanistan from the disease early warning system 2009-2015," PLoS One, vol. 12, no. 6, e0178677, pp. 1-12, 2017.

[31] A. N. M. A. Ali, "Food safety and public health issues in Bangladesh: a regulatory concern," European Food and Feed Law Review, vol. 8, no. 1, pp. 31-40, 2013.

[32] S. El-Saharty, K. Z. Ahsan, T. L. Koehlmoos and M. M. Engelgau, "Tackling non-communicable diseases in Bangladesh now is the time," The World Bank, Vol. 1, no. 80752, pp. 1-120, 2013.

[33] N. Dorji, M. P. Dunne, C. Seib and S. Deb, "Quality of life among senior citizens in Bhutan: Associations with adverse life experiences, chronic diseases, spirituality, and social connectedness," Asia Pacific Journal of Public Health, vol. 29, no. 1, pp. 35-46, 2017.

[34] S. Thinley, P. Tshering, K. Wangmo, N. Wangchuk, T. Dorji et al., "The Kingdom of Bhutan health system review," Institutional Repository for Information Sharing (IRIS), vol. 7, no. 2, 2017.

[35] V. R. Dhara, P. J. Schramm and G. Luber, "Climate change \& infectious diseases in India: Implications for health care providers," Indian Journal of Medical Research, vol. 138, no. 6, pp. 847-852, 2013.

[36] U. Shrivastava, A. Misra, V. Mohan, R. Unnikrishnan and D. Bachani, "Obesity, diabetes and cardiovascular diseases in India: public health challenges," Current Diabetes Reviews, vol. 13, no. 1, pp. 65-80, 2016.

[37] H. A. N. Ibrahim and A. Mathur, "Climate change and health in Maldives: protecting our common future," WHO South-East Asia Journal of Public Health, vol. 6, no. 2, pp. 15-22, 2017.

[38] M. K. Shrestha, C. W. Guo, N. Maharjan, R. Gurung and S. Ruit, "Health literacy of common ocular diseases in Nepal," BMC Ophthalmology, vol. 14, no. 1, pp. 375, 2014.

[39] R. S. Jayasekara and T. Schultz, "Health status, trends, and issues in Sri Lanka," Nursing \& Health Sciences, vol. 9, no. 3, pp. 228-233, 2007.

[40] C. Robertson, K. Sawford, S. L. Daniel, T. A. Nelson and C. Stephen, "Mobile phone-based infectious disease surveillance system, Sri Lanka," Emerging Infectious Diseases, vol. 16, no. 10, pp. 1524-1531, 2010.

[41] J. Ahmed and B. T. Shaikh, "The state of affairs at primary health care facilities in Pakistan: where is the State's stewardship?" Eastern Mediterranean Health Journal, vol. 17, no. 07, pp. 619-623, 2011.

[42] M. Khadim, "Health in Pakistan: Understanding the major issues, transparent hands," 2019. [Online]. Available: https://www.transparenthands.org/list-of-top-15-health-issues-in-pakistan/.

[43] H. A. Muhammad, T. J. Muhammad, U. K. B. Sami, T. Narmeen and T. Aira, "Major health issues in Pakistan," Technology Times, 2019. [Online]. Available: https://www.technologytimes.pk/2019/07/12/major-healthissues-pakistan/.

[44] D. M. Khan, N. Asghar, I. Ali and W. A. Khan, "The frequency of various diseases among patients attending Tehsil Headquarter Hospital Khwazakela," Swat JPMA, vol. 69, no. 9, pp. 1369-1371, 2019.

[45] K. Khan, Y. Lu, M. A. Saeed, H. Bilal, H. Sher et al., "Prevalent fecal contamination in drinking water resources and potential health risks in Swat, Pakistan," Journal of Environmental Sciences, vol. 72, no. 1, pp. 1-12, 2018. 
[46] V. S. Kumar and P. Munusamy, "Uses and importance of mobile commerce: An overview," Studies in Indian Place Names, vol. 40, no. 12, pp. 703-710, 2020.

[47] M. Bonabi, S. Z. Mohebbi, E. A. Martinez-Mier, T. P. Thyvalikakath and M. R. Khami, "Effectiveness of smart phone application use as continuing medical education method in pediatric oral health care: A randomized trial," BMC Medical Education, vol. 19, no. 1, pp. 334, 2019.

[48] J. Valle, T. Godby, D. P. Paul III, H. Smith and A. Coustasse, "Use of smart phones for clinical and medical education," Health Care Manager, vol. 36, no. 3, pp. 293-300, 2017.

[49] M. Z. Latif, I. Hussain, R. Saeed, M. A. Qureshi and U. Maqsood, "Use of smart phones and social media in medical education: Trends, advantages, challenges and barriers," Acta Informatica Medica, vol. 27, no. 2, pp. 133-138, 2019.

[50] P. A. Guze, "Using technology to meet the challenges of medical education," Transactions of the American Clinical and Climatological Association, vol. 126, pp. 260-270, 2015.

[51] B. Kołodziejczak, M. Roszak, W. Kowalewski and A. Ren-Kurc, "Educational multimedia materials in academic medical training," Studies in Logic, Grammar and Rhetoric, vol. 39, no. 1, pp. 105-122, 2014.

[52] J. Yoon, L. Hagen, J. Andrews, R. Scharf, T. Keller et al., "On the use of multimedia in Twitter health communication: Analysis of tweets regarding the Zika virus," Information Research, vol. 24, no. 2, 823, pp. $1-12,2019$.

[53] K. J. Kim and G. Kim, "Development of e-learning in medical education: 10 years' experience of Korean medical schools," Korean Journal of Medical Education, vol. 31, no. 3, pp. 205-214, 2019.

[54] M. Al-Balas, H. I. Al-Balas, H. M. Jaber, K. Obeidat, H. Al-Balas et al., "Distance learning in clinical medical education amid COVID-19 pandemic in jordan: Current situation, challenges, and perspectives," $B M C$ Medical Education, vol. 20, no. 1, pp. 1-7, 2020.

[55] M. C. Huang, C. H. Hung, C. Y. Yu, D. C. Berry, S. J. Shin et al., "The effectiveness of multimedia education for patients with type 2 diabetes mellitus," Journal of Advanced Nursing, vol. 73, no. 4, pp. 943-954, 2017.

[56] T. Chatterley and D. Chojecki, "Personal digital assistant usage among undergraduate medical students: exploring trends, barriers, and the advent of smartphones," Journal of the Medical Library Association: JMLA, vol. 98, no. 2, pp. 157-160, 2010.

[57] C. Hanson, J. West, B. Neiger, R. Thackeray, M. Barnes et al., "Use and acceptance of social media among health educators," American Journal of Health Education, vol. 42, no. 4, pp. 197-204, 2013.

[58] C. L. Ventola, "Social media and health care professionals: Benefits, risks, and best practices," Pharmacy and Therapeutics, vol. 39, no. 7, pp. 491-499, 2014.

[59] C. Costa-Sánchez and M. I. Míguez-González, "Use of social media for health education and corporate communication of hospitals," El Profesional de la Información, vol. 27, no. 5, pp. 1145-1154, 2018.

[60] I. Herrera-Peco and J. C. de la Torre-Montero, "Preface of special issue cares in the age of communication: Health education and healthy lifestyles: Social media and health communication in a pandemic?" Europe Journal of Investigation in Health, Psychology and Education, vol. 10, no. 2, pp. 575-578, 2020.

[61] E. M. McDougall, "Simulation in education for health care professionals," British Columbia Medical Journal (BCMJ), vol. 57, no. 10, pp. 444-448, 2015.

[62] B. Gücükoğlu, D. Y. Ceylan, P. E. Şenyuva, P. H. Kaya and G. Bodur, "An example of the patient education course," Istanbul University Rectorate Publication, vol. 1, no. 1, pp. 29-41, 2014.

[63] S. Leslie, "Designing an interactive web-based tutorial for health sciences students: A collaborative library project," Medical Reference Services Quarterly, vol. 36, no. 1, pp. 90-96, 2017.

[64] B. O’Dea, C. King, M. Subotic-Kerry, K. O’Moore and H. Christensen, "School counselors' perspectives of a web-based stepped care mental health service for schools: Cross-sectional online survey," JMIR Mental Health, vol. 4, no. 1, pp. e1, 2017.

[65] S. Beniczky, I. Blümcke, S. Rampp, P. Shisler, E. Biesel et al., "e-learning comes of age: Web-based education provided by the International League Against Epilepsy," Epileptic Disorders, vol. 22, no. 3, pp. 237-244, 2020. 
IASC, 2021, vol.28, no.1

[66] P. Pype, F. Mertens, F. Helewaut and D. Krystallidou, "Healthcare teams as complex adaptive systems: understanding team behaviour through team members' perception of interpersonal interaction," BMC Health Services Research, vol. 18, no. 1, pp. 685, 2018.

[67] P. S. K. Patra, D. P. Sahu and I. Mandal, "An expert system for diagnosis of human diseases," Int. Journal of Computer Applications, vol. 1, no. 13, pp. 71-74, 2010.

[68] H. U. Rahman, N. A. Sangi and M. U. Ahmed, "Identification of basic health information and knowledge at high schools in Swat rural areas (a way toward VEBH model implementation)," Jurnal Pendidikan Terbuka Dan Jarak Jauh, vol. 20, no. 2, pp. 61-73, 2019.

[69] N. A. Sangi and H. U. Rahman, "VEBH: Virtual Education for Basic Health model in high school level," in Proc. Int. Conf. on Education and Learning'17 DAKAM (Eastern Mediterranean Academic Research Center) Education April 21, Published in Social Sciences Proceedings Book, pp. 64-75, 2017.

[70] N. A. Sangi and H. ur Rahman, "Utilization of electronic learning system in Swat rural areas," Sukkur IBA Journal of Computing and Mathematical Sciences, vol. 1, no. 2, pp. 109-115, 2017.

[71] N. A. Sangi and M. U. Ahmed, "Olive framework for e-learning development at AIOU," Pakistan Journal of Information Communication Technologies and Robotic Applications, vol. 41, pp. 117-140, 2018.

[72] S. Kocakaya and S. Gonen, "The effects of computer-assisted instruction designed according to 7E model of constructivist learning on physics student teachers' achievement, concept learning, self-efficacy perceptions and attitudes," Turkish Online Journal of Distance Education, vol. 11, no. 3, pp. 206-224, 2010.

[73] M. T. Sørensen, "The students' choice of technology a pragmatic and outcome-focused approach," in The Digital Turn in Higher Education, D. Kergel, B. Heidkamp, P. Telléus, T. Rachwal, S. Nowakowski, Wiesbaden: Springer VS, pp. 161-174, 2018. 